\title{
Formalizing the Role of Social Capital on Individuals' Continuous Use of Social Networking Sites from a Social Cognitive Perspective
}

\author{
Yu Guo, Yiwei Li, Naoya Ito \\ Hokkaido University
}

\begin{abstract}
By integrating useful insights from social cognitive theory and social capital theory, we aim to develop a model for better understanding people's behaviors related to the use of social networking sites (SNSs) and formalize the role of social capital in individuals' continuous SNS use. Propositions that emphasize the triadic interactive relationships among environmental, personal, and behavioral factors were highlighted in this study. After reviewing previous studies, in this paper we proposed the following: (1) the causation between SNS use and individuals' perceived social capital might be mutual; social capital may not only be the result of media selectivity, but could also be an essential stimulus initiating the start of using SNSs; (2) the influences of SNSs use on the generation of individuals' online social capital might be conditional upon particular patterns of use; (3) both the level of dependence on SNSs and the differentiated patterns of SNSs use vary according to individuals' perceived offline social capital and their personal characteristics, for instance, personality or self-construal, and social anxiety.
\end{abstract}

Key Words: Computer-mediated communication; social capital; social cognitive theory; social networking sites (SNSs); media usage 


\section{Introduction}

The use of social networking sites (SNSs) has become a global phenomenon in recent years. Take the most representative social networking site Facebook as an example: By the end of 2012 Facebook had already attracted over 1 billion active users who visit their website every month (AP, 2012). If Facebook were a country, its 1.155 billion users would make it the third largest population in the world. With the increasing popularity of SNSs around the world, it also triggers researchers' curiosity about why people choose to use them, how they use them, and what kind of influence it may have. These questions perhaps have been raised in numerous prologues introducing a new phenomenon's birth, diffusion, and development, but when we propose them in the context of computermediated communication (CMC), it is difficult for us to find answers in the current knowledge and paradigms. The cause of these difficulties may be related to the fact that it is a challenge to combine the existing communication theories into one framework.

After decades of development, communication as an independent discipline has offered us a variety of fundamental research that have been called the milestones, and these studies have been considered as useful explanations in helping us to better understand media influence. However, due to the lack of a unified theory, these explanations also result in a fragmental research tendency, which focused on the relationships between input and output variables to demonstrate elaborate stimulusresponse models. Moreover, beginning with the diffusion of the informational communication technologies (ICTs) around the 1990s, a series of novel communication tools based on ICTs have penetrated into almost every corner of our life and become the essential avenues for us to access information, maintain social relations, and find something fun. Especially in recent years, the emergence of SNSs has greatly changed the pattern of communication and provided a new channel allowing people to be more flexible as they socialize and interact with each other (Moore \& McElroy, 2012).

Although a growing body of previous studies following the traditional approach (uses and gratifications theory) have provided much empirical evidence for understanding SNSs users' motivation, behavior, and the social-psychological consequences of SNS use, there has been a limited effort made to synthesize media selectivity and its effect in a comprehensive model. CMC researchers claim that Internetbased communication will not develop its patterns by following conventions, but the new 
appearing conceptual approaches are currently revolutionizing our life to enrich CMC models (Harris, 2009; LaRose \& Eastin, 2004). Studies about the relationship between SNS use and its socio-psychological effect on individuals will undoubtedly help us to figure out new media's role in cultivating our society and changing our lives. In this paper, insights were drawn from both the social capital theory and the social cognitive theory. By reviewing studies surrounding SNSs, we also discussed the limitations of existing research. This paper is an attempt to suggest following studies concentrating more on potential mutual causality between social media use and individuals' social and psychological status, for instance, interpersonal relations and perceived life satisfaction.

\section{Why suggest a social-cognitive approach?}

During the first half of the twentieth century, researchers became aware of media's potential influence on shaping individuals' perception. Considering the media's power for propaganda and political election, research on media effect started with several milestones and demonstrated a shifting picture from bullet theory to limited media effects model. These classic models were extensively used in following studies helping us to explore the media's role in the mass society system. However, with the emergence of the Internet, it is found that the Internet created a novel communication model, which includes features of interpersonal communication, organizational communication, and mass communication. Therefore, the traditional research model may not be powerful enough to interpret the new communication pattern.

One of the major limitations in the previous media effect research is that researchers put too much effort into picking up input and output variables to examine the causal relations, but neglected to draw a comprehensive picture of media effect which should include the occurrence, development, amplification, and attenuation of the effect (Bryant, Thompson, \& Finklea, 2002). For example, in the early 1990s, computer specialists and social researchers rushed into the examination of the Internet's big role on people and society. There were numerous studies discussing whether Internet use would bring negative or positive effects to people's social relations (Shah, 2001), civic participation (Boulianne, 2009; Shah, Cho, Eveland, \& Kwak, 2005), life quality (Stepanikova, Nie, \& He, 2010), and psychological wellbeing (Gross, Juvonen, \& Gable, 
2002; Shaw \& Gant, 2002). Such linear hypotheses testing continued to be adopted in the research of SNSs. However, the problem is that we discussed the media as a stimulus excessively. We still have abundant questions concerning the process of media effect that have not been adequately answered. For instance, we might ask what kind of effect there is: self-contained or cumulative; how it happens: directly or indirectly; how long it will last: fleeting or lasting. Also, by seeing the medium as an external stimulus, early research overlooked individuals internal drivers of media use, which could also be seen as a limitation of the current paradigm (Lang, 2013),

Unlike the stimulus-response model, the social cognitive theory emphasizes the triadic, dynamic, and reciprocal interactions among the personal, behavioral, and environmental factors that influence human functioning (Bandura, 2002). The three factors influence each other with varying strength (see Figure 1). From the view of socialcognitive perspective, humans are proactive and self-motivated agencies that are selforganizing, self-reflecting, and self-regulating in the process of development. Consistent with the uses and gratifications theory (U\&G), the social cognitive theory (SCT) also sees individuals as initiative audiences that would select specific media settings to meet their particular needs. However, different from U\&G, which obtained factored motivations of media use, SCT proposed the concept of "expectation" as a behavior incentive and divided such incentives into six categories: novel sensory, social, status, monetary, enjoyable activity, and self-reactive incentives (Bandura, 2002). Compared with U\&G, it more precisely reflects the full range of individuals' inner drivers of media use (LaRose \& Eastin, 2004).

Figure 1

The triadic model of SCT (Bandura, 2002)

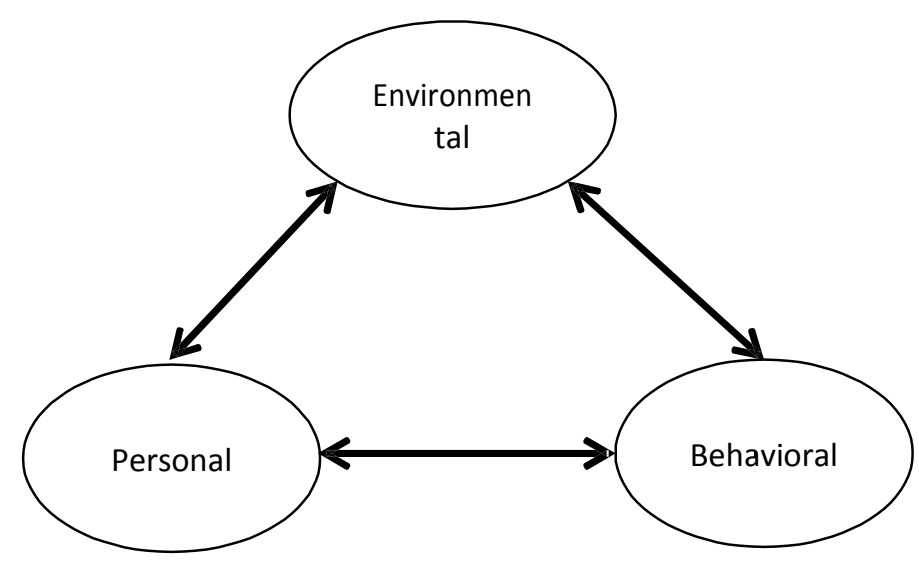


One major merit of SCT is that it provides a strong framework for investigating the influence of individuals' intrinsic characteristics on their environment. The environmental variable has been commonly seen as an essential determinant of media use behaviors. However, we should also consider the opposite effect that continuous use of media might contribute to variance in the environmental variable. Taking the use of SNSs as an example, at the beginning, individuals' trust of their SNS community might result in their self-disclosure of behavior, but with continued use of the SNS, their trust in the community might be strengthened. Moreover, through frequent interactions with other SNS members, a particular community culture might be generated from members' behavior on SNS. As noted in the literature, humans are both products and producers of their environment (Bryant et al., 2002), and the media are more likely to proceed an environmental-mediated effect. From this view, we argue that, rather than being the determinant, the media play an essential role in influencing the strength, duration, and pattern of the interplay between people and environment. Considering this, the triadic reciprocal model of SCT offers us a theoretical support for deepening our understanding of the relationships among social media use, personal characteristics, and the external environment.

\section{Taking social capital as both outcome and predictor}

Regarding studies on social media's effect on personal relationship, Ellison has conducted several pioneering research projects since 2007 (Ellison, Steinfield, \& Lampe, 2007, 2011), which generated an increasing enthusiasm in discussions about the relationship between social media use and individuals' perceived social capital ( Antoci, Sabatini, \& Sodini, 2011; Chang \& Zhu, 2012; Guo, Li, \& Ito, 2013). We cannot deny early endeavors, but the linear way of thinking also leads to a problem. There is a precondition in existing assumptions that they only take social capital as an outcome of social media use, which may narrow future thoughts. Regarding a new media context, this precondition, at the same time, leaves us two questions in need of further consideration. One is whether social capital is a cause of continuous use of media rather than merely being its outcome. The other one is whether the intensively applied measurement of social media use, such as amount of time and frequency, can be seen as key variables leading to certain social and 
psychological consequences. Besides these factors, what other variables of social media use should we consider?

Social capital theory was constructed on the observation of individuals' social network and social relations. It was popularized to describe the accumulated social resources and benefits embedded in interpersonal relations, communities, networks, and societies (Chang \& Chuang, 2011; Coleman, 1988). It was also described as the social glue to connect individuals, multifarious networks, and communities together as a whole (Ellison et al., 2007). The social capital theory provided us a theoretical framework to understand whether and how individuals' social relations were affected by the use of media (Sum, Mathews, Pourghasem, \& Hughes, 2008). With the popularization of the Internet, the relationship between social capital and the use of Internet was intensively debated. At an earlier time, the use of the Internet was generally considered to play a negative role in producing individuals' social capital and psychological wellbeing. Based on the time displacement hypothesis, researchers argued that Internet users consume particular media content related to their personal interests, which might reduce their participation in real world activities (Kraut et al., 1998). However, this pessimistic view is not supported by much empirical evidence. Contradictorily, use of the Internet for interpersonal communication might be a supplement to face-to-face interactions (Wellman, Haase, Witte, \& Hampton, 2001).

Some scholars developed the discussion by analyzing differentiated patterns of Internet use. As noted by Williams (2007), use of the Internet is neither a panacea nor the problem; the examination of its influences should consider individuals' personality and particular patterns of use. Subsequently, it has been supported that individuals' Internet use varies within the specific environment they are exposed to (Guo et al., 2013). The use of CMC tools for social and informational purposes may generate positive outcomes, while the use for entertainment and recreational purposes may have a negative influence (Weiser, 2001). Additionally, patterns of social media use and its association with outcomes may differ according to differentiated personalities (Amichai-Hamburger \& Vinitzky, 2010; Moore \& McElroy, 2012; Ross et al., 2009). For example, findings of Amichai-Hamburger and Vinitzky's study (2010) demonstrated a significant relationship between the big five personality traits and Facebook behaviors. Kim, Hsu, and Gil de Zuniga (2013) explored the moderating role of personality in the effect of social media 
use on discussion network heterogeneity and civic engagement. Their findings indicated that users who scored low on extraversion and openness to experience might be more easily engaged online than individuals with high level of extraversion and openness. These studies support assumptions of SCT, which address that the fundamental cause of attitudinal and behavioral change is probably not the influence of mass media, but the immediate environment they are embedded in as well as the intrinsic prosperities they possess (Bandura, 2002).

Considering this, we put forward two propositions.

\section{Proposition 1:}

Individuals' intrinsic characteristics and their patterns of social media use will affect the relationship between their behavior in using SNS and perceived social capital, which means the effect of social media use on social relations will depend on how an individual uses social media and what kind of person he or she is.

Besides the studies providing insightful findings for better understanding of how CMC settings affect social relations, other studies also take the opposite way of thinking. Because of individuals' social media use, the favorable benefits on their social relations may in turn enhance their motivation to use it. For instance, Chiu, Hsu, and Wang (2006) suggested that individuals' perceived social capital in virtual communities significantly affected their online knowledge sharing behaviors. Moreover, according to the diffusion and innovation proposition, the diffusion of innovations relies on the size of individuals' social network, which means people with larger social networks may more easily adopt innovations than those with few social relationships (Rogers, 2010). Therefore, we argue that the fundamental reason for individuals to adopt new technology might be the influence from their social networks. When people find others around them are all using the same new communication tool, they will probably try it too. On the basis of social capital theory, we assume that social capital generated online may become an essential incentive that causes continuous social media use. However, unlike conventional opinions arguing the continuous use is driven by continuous satisfaction from the experience, we don't think the formulation of online social capital is equal to a certain kind of needs to be satisfied. One of the considerations is that, apparently, "online social capital" is a new product of the use of Internet-based tools. Before we have identified 
whether it is an outcome or a stimulus, it might be risky to equate the new phenomenon to the conventional concept.

Actually, rather than taking social capital as a gratification of behavior, it might be more plausible and insightful to rethink its role from the social-cognitive perspective and take it as individuals' perception of environmental support. For instance, Cemalcilar, Falbo, and Stapleton (2005) investigated how computer-mediated communication (CMC) technologies influenced the acculturation of international students. They found that the social support gained from the use of CMC tools determined individuals' physical and mental status, and thus fostered behavior change to meet certain environmental demands in acculturation.

Therefore, to achieve a better understanding of the mutual interaction between social media use and social relationships, we suggest the following proposition by also considering perceived social capital as a potential environmental factor:

\section{Proposition 2:}

Individuals' social capital is not only an outcome of social media use; it will also in turn influence individuals' continuous use of social media.

As shown in Figure 2, people get benefits from social media use, which will enable them to have a stronger desire to use it in the future.

Figure 2

Mutual affecting process of social media use and social capital

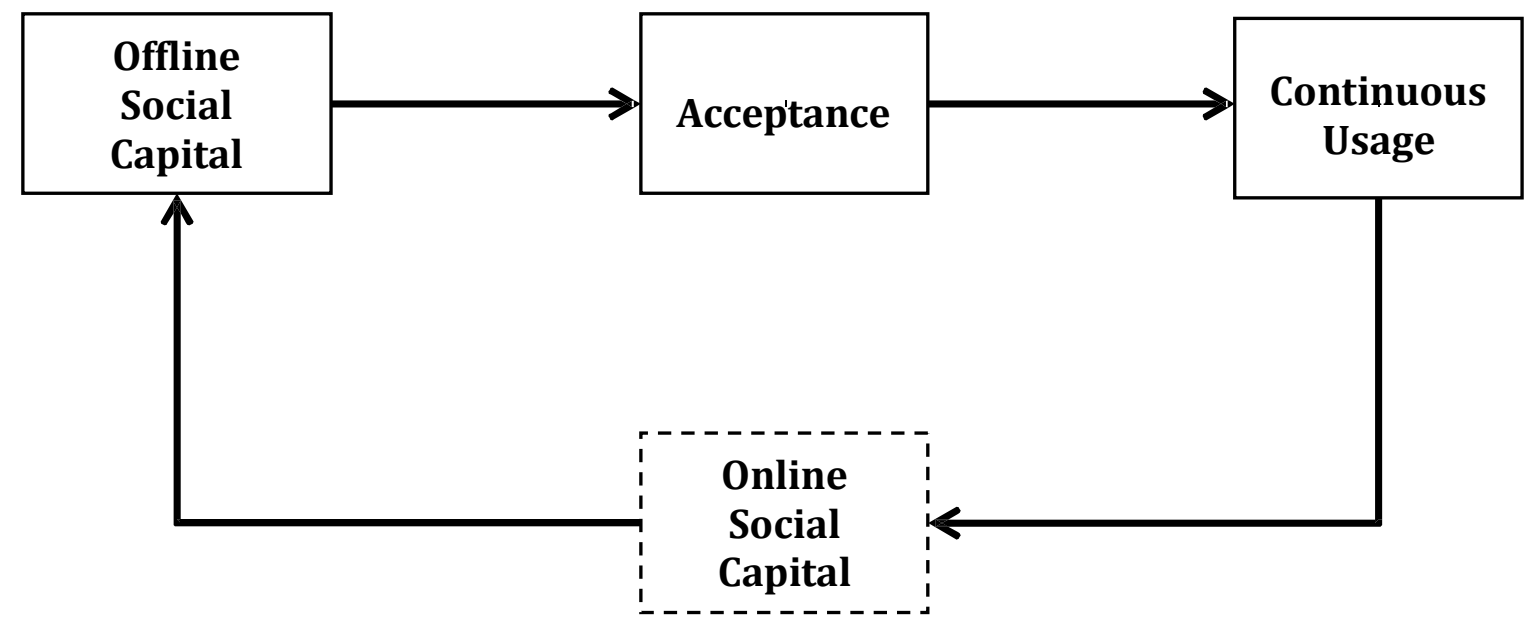




\section{Limitations of the existing framework and future directions}

Through our literature review, we found three major limitations of previous studies.

First, discussions about social media effects are primarily based on a linear stimulus and response model, ignoring the potential influence of environmental and personal factors. Future studies should consider variables representing individuals' intrinsic characteristics such as personality, self-construal, and social anxiety, which may moderate or mediate the effect of media.

Second, there are rare cases exploring the dynamic and longitudinal cause and effect of media use. In the absence of such examination, it is difficult to decide the independent variable and the outcome variable of causation. Also, although we know there is a significant relationship between social media use and perceived social capital, it is still difficult to answer how long the effect will last and what kind of change might occur. Therefore, longitudinal methods should be considered in the follow-up studies.

Last, previous studies viewed social capital as an outcome of social media use. However, as discussed above, social capital might also become the reason for individuals' social media behaviors, since the process of media selectivity and media effect might be reciprocal and mutually influential. Therefore, the next step should be an attempt to invite individuals' perceived social capital as independent variables to predict their continuous use of social media. 
Figure 3

A longitudinal model of the interactive process of media use and social capital $(E=$ environmental factor; $P=$ personal characteristic; $U=$ use of social media; $S=$ perceived social capital)

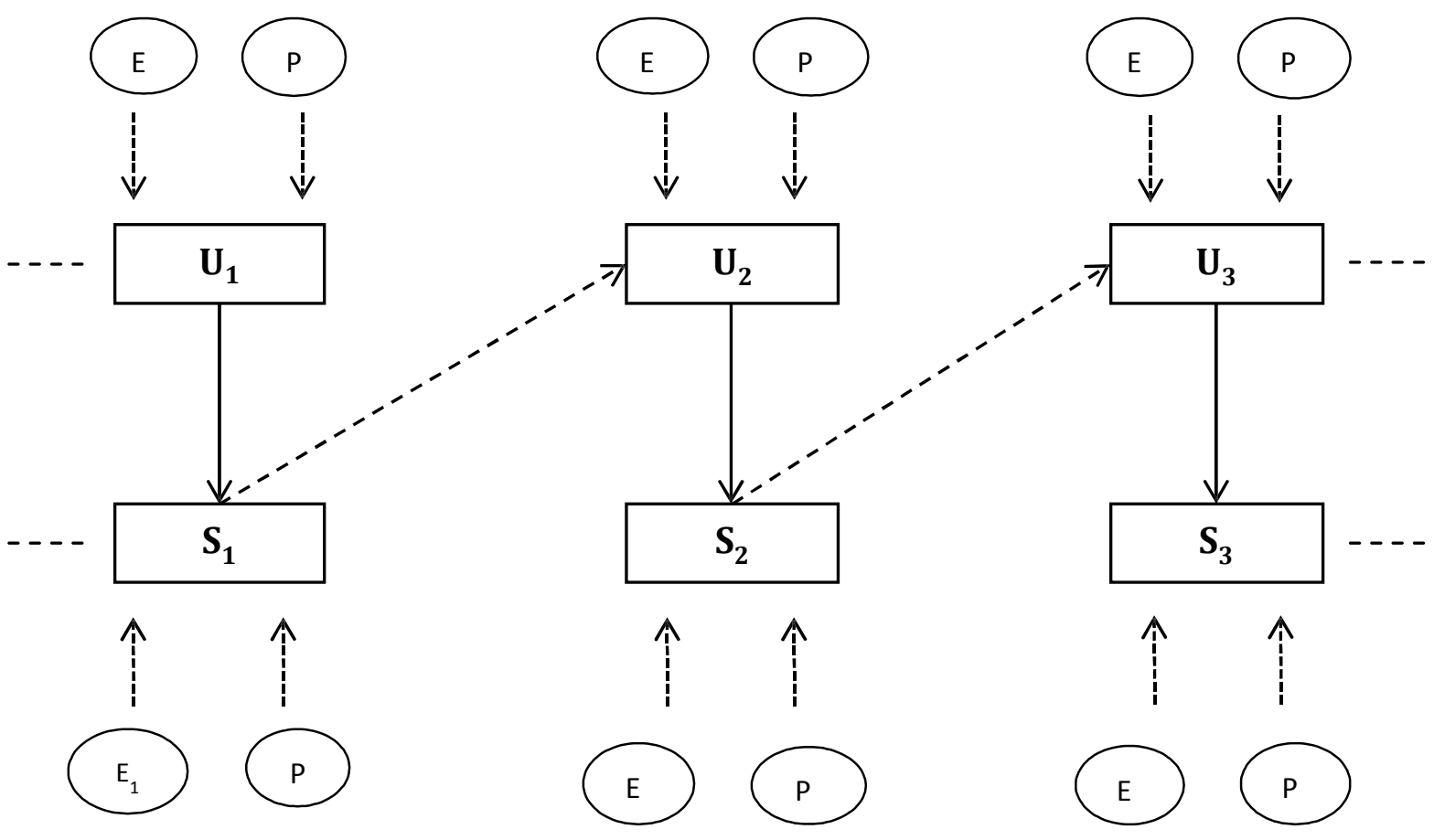

This article aims to develop a more comprehensive model to synthesize the causal relationship between social media use and individuals' social relation in the big picture. As shown in Figure 3, the proposed model has fully considered the mutual interaction between the two variables in a longitudinal process. In addition, as we argued, current research has over weighted the determining role of media use, but failed to notice the influence of individuals' personal characteristics and particular environment. To reduce this limitation, we therefore assume that social capital that individuals already have might be a major force to encourage them to use social media. During the experience of SNS use, social capital generated through online behavior, which is a unique social phenomenon in need of further investigation, may then become a predictor of continuous use. Future empirical research is needed to provide support for this model. However, we have concerns that data from general surveys may not be strong enough to interpret the proposed associations. Efforts should also be made on the exploration of rigorous methodologies. 


\section{References}

Amichai-Hamburger, Y., \& Vinitzky, G. (2010). Social network use and personality. Computers in Human Behavior, 26(6), 1289-1295.

Antoci, A., Sabatini, F., \& Sodini, M. (2011). See you on Facebook! A framework for analyzing the role of computer-mediated interaction in the evolution of social capital. Department of Communication, University of Teramo.

AP. (2012). Number of active users at Facebook over the years. Retrieved September, 20, 2013, from http://news.yahoo.com/number-active-users-facebook-over230449748.html

Bandura, A. (2002). Social cognitive theory of mass communication. In J. Bryant, \& D. Zillmann (Eds.), Media effects: Advances in theory and research (pp. 121-153). Mahwah, New Jersey: Lawrence Erlbaum Associates.

Boulianne, S.. (2009). Does Internet use affect engagement? A meta-analysis of research. Political Communication, 26(2), 193-211.

Bryant, J., Thompson, S., \& Finklea, B. W. (2002). Fundamentals of media effects: McGraw-Hill Nueva York, NY: Waveland Press.

Cemalcilar, Z., Falbo, T., \& Stapleton, L. M. (2005). Cyber communication: A new opportunity for international students' adaptation? International Journal of Intercultural Relations, 29(1), 91-110.

Chang, H. H., \& Chuang, S.-S. (2011). Social capital and individual motivations on knowledge sharing: Participant involvement as a moderator. Information \& Management, 48(1), 9-18.

Chang, Y. P., \& Zhu, D. H.. (2012). The role of perceived social capital and flow experience in building users' continuance intention to social networking sites in China. Computers in Human Behavior, 28(3), 995-1001.

Chiu, C.M., Hsu, M.H., \& Wang, E.T.G. (2006). Understanding knowledge sharing in virtual communities: An integration of social capital and social cognitive theories. Decision Support Systems, 42(3), 1872-1888.

Coleman, J. S. (1988). Social capital in the creation of human capital. American Journal of Sociology, S95-S120.

Ellison, N. B., Steinfield, C., \& Lampe, C. (2007). The benefits of Facebook "friends:" Social capital and college students' use of online social network sites. Journal of Computer-Mediated Communication, 12(4), 1143-1168.

Ellison, N. B., Steinfield, C., \& Lampe, C. (2011). Connection strategies: Social capital implications of Facebook-enabled communication practices. New Media \& Society, 13(6), 873-892.

Gross, E. F., Juvonen, J., \& Gable, S. L. (2002). Internet use and well-being in adolescence. Journal of Social Issues, 58(1), 75-90.

Guo, Y., Li, Y., \& Ito, N.. (2013). Exploring the predicted effect of social networking site use on perceived social capital and psychological well-being of Chinese international students in Japan. Cyber Psychology, Behavior, and Social Networking, 17(1), 52-58. 
Harris, R. J. (2009). A cognitive psychology of mass communication. (5th ed). NY: Taylor \& Francis.

Kim, Y., Hsu, S.-H., \& Gil de Zuniga, H. (2013). Influence of social media use on discussion network heterogeneity and civic engagement: The moderating role of personality traits. Journal of Communication, 63(3), 498-516.

Kraut, R., Patterson, M., Lundmark, V., Kiesler, S., Mukophadhyay, T., \& Scherlis, W. (1998). Internet paradox: A social technology that reduces social involvement and psychological well-being? American Psychologist, 53(9), 1017.

Lang, A. (2013). Discipline in Crisis? The Shifting Paradigm of Mass Communication Research. Communication Theory, 23(1), 10-24.

LaRose, R., \& Eastin, M.S. (2004). A social cognitive theory of Internet uses and gratifications: Toward a new model of media attendance. Journal of Broadcasting \& Electronic Media, 48(3), 358-377.

Moore, K., \& McElroy, J. C. (2012). The influence of personality on Facebook usage, wall postings, and regret. Computers in Human Behavior, 28(1), 267-274.

Rogers, E. M. (2010). Diffusion of innovations: Simon and Schuster.

Ross, C., Orr, E. S, Sisic, M., Arseneault, J. M., Simmering, M. G., \& Orr, R. R. (2009). Personality and motivations associated with Facebook use. Computers in Human Behavior, 25(2), 578-586.

Shah, D. V., Cho, J., Eveland, W. P., \& Kwak, N.. (2005). Information and expression in a digital age modeling Internet effects on civic participation. Communication Research, 32(5), 531-565.

Shah, D. V., Kwak, N., Holbert, R. (2001). "Connecting" and "disconnecting" with civic life: Patterns of Internet use and the production of social capital. Political communication, 18(2), 141-162.

Shaw, L. H., \& Gant, L. M. (2002). In defense of the Internet: The relationship between Internet communication and depression, loneliness, self-esteem, and perceived social support. CyberPsychology \& Behavior, 5(2), 157-171.

Stepanikova, I., Nie, N. H., \& He, X.. (2010). Time on the Internet at home, loneliness, and life satisfaction: Evidence from panel time-diary data. Computers in Human Behavior, 26(3), 329-338.

Sum, S., Mathews, M., Pourghasem, M., \& Hughes, I. (2008). Internet technology and social capital: How the Internet affects seniors'social capital and wellbeing. Journal of Computer-Mediated Communication, 14(1), 202-220.

Weiser, E. B. (2001). The functions of Internet use and their social and psychological consequences. CyberPsychology \& Behavior, 4(6), 723-743.

Wellman, B., Haase, A. Q., Witte, J., \& Hampton, K. (2001). Does the Internet increase, decrease, or supplement social capital? Social networks, participation, and community commitment. American Behavioral Scientist, 45(3), 436-455.

Williams, D. (2007). The impact of time online: Social capital and cyberbalkanization. CyberPsychology \& Behavior, 10(3), 398-406. 


\section{Biographical Notes}

Yu Guo is a $\mathrm{PhD}$ candidate enrolled in the Graduate School of International Media, Communication, and Tourism Studies (IMCTS) at Hokkaido University in Japan. His research interests are mainly on computer-mediated communication (CMC) and intercultural studies.

He can be reached at: guoyu@imc.hokudai.ac.jp

Yiwei Li is a PhD candidate enrolled in the Graduate School of International Media, Communication, and Tourism Studies (IMCTS) at Hokkaido University in Japan. Her research interest is risk communication.

She can be reached at: yiweili@imc.hokudai.ac.jp

Naoya Ito is a professor in the Research Faculty of Media and Communication at Hokkaido University in Japan.

He can be reached at: naoya@imc.hokudai.ac.jp

Date of the submission: $2013-12-01$

Date of the review result: 2014-01-14

Date of the decision: 2014-01-21 